\title{
Hydrocarbon-soluble inhibitors of metal corrosion. Part 3. Dependence of the inhibitive efficiency and adsorptivity of oleic acid amides and salts on their physicochemical parameters
}

\author{
A.I. Altsybeeva, E.A. Tronova and V.V. Burlov \\ OOO NPO NEPhTEKhIM, ul. Pulkovskaya 10, St. Petersburg, 196158 Russian Federation \\ E-mail: altsybeeva@yandex.ru
}

\begin{abstract}
Correlation analysis of the dependence of the inhibitive efficiency (determined from electrochemical measurement data) and adsorption capability (determined from the changes in the junction potential difference upon formation of an adsorption film on a metal from inhibitor solutions) on the physicochemical parameters has been performed for a number of amides and salts obtained from the same amines and differing in the number and arrangement of nitrogen atoms in the molecules. A prediction is given for the efficiency of a mono-substituted piperazine amide - a corrosion inhibitor for carbon steel and copper.
\end{abstract}

Key words: correlation analysis, efficiency prediction, oleic acid amides and salts.

Received: December 17, 2015. Published: January 17, 2016.

doi: $\underline{10.17675 / 2305-6894-2016-5-1-4}$

Let us analyze the dependence of the inhibitive efficiency and electron-donating capability of amides and salts on the main physicochemical parameters of the inhibitors.

Tables 1 and 2 list the corrosion and adsorption parameters and the main physicochemical parameters of oleic acid amides and salts.

Table 1. The main corrosion, adsorption and physicochemical parameters of oleic acid amides.

\begin{tabular}{ccccccccc}
\hline Amide of: & $\boldsymbol{\gamma}$ & $\begin{array}{c}\Delta \mathbf{J P D} \\
\mathbf{s t e e l}\end{array}$ & $\boldsymbol{q}\left(\mathrm{N}_{\mathrm{sp}^{3}}\right)$ & $\begin{array}{c}\boldsymbol{q} \\
\left(\mathrm{O}_{\mathrm{sp}^{3} \text { ring }}\right)\end{array}$ & $\boldsymbol{q}\left(\mathrm{O}_{\mathrm{sp}^{2}}\right)$ & $\boldsymbol{\Sigma} \boldsymbol{q}$ & $\boldsymbol{\pi}$ & $\boldsymbol{\mu}$ \\
\hline Hexylamine & 4.6 & 154 & -0.212 & - & -0.372 & -0.584 & 9.36 & 4.0 \\
Cyclohexylamine & 12.5 & 203 & -0.216 & - & -0.363 & -0.579 & 8.83 & 3.6 \\
Morpholine & 104 & 256 & -0.155 & -0.222 & -0.373 & -0.750 & 6.47 & 3.0 \\
Piperidine & 100 & 98 & -0.165 & - & -0.375 & -0.540 & 7.15 & 3.6 \\
Piperazine (mono) & 7.35 & 94 & -0.168 & - & -0.375 & -0.715 & 5.06 & 3.7 \\
\hline
\end{tabular}


Table 2. The main corrosion, adsorption and physicochemical parameters of amine salts of oleic acid.

\begin{tabular}{|c|c|c|c|c|c|c|c|c|c|}
\hline Salt of: & $\gamma$ & $\begin{array}{c}\Delta \mathrm{JPD} \\
\text { steel }\end{array}$ & $q\left(\mathrm{~N}_{\mathrm{sp}^{3}}\right)$ & $\left(\mathrm{O}_{\mathrm{sp}^{3} \text { ring }}^{q}\right)$ & $q\left(\mathrm{O}_{\mathrm{sp}^{2} \text { salt }}\right)$ & $q\left(\mathrm{O}_{\mathrm{sp}^{3} \text { salt }}\right)$ & $\Sigma q$ & $\pi$ & $\boldsymbol{\mu}$ \\
\hline Hexylamine & 9.9 & 103 & +0.406 & - & -0.325 & -0.281 & -0.200 & 3.63 & 2.5 \\
\hline Cyclohexylamine & 8.3 & 148 & +0.361 & - & -0.376 & -0.326 & -0.341 & 3.82 & 2.0 \\
\hline Morpholine & 28.1 & 195 & +0.351 & -0.219 & -0.353 & -0.372 & -0.593 & -1.24 & 1.4 \\
\hline Piperidine & 35.4 & 111 & +0.341 & - & -0.354 & -0.393 & -0.406 & -1.49 & 3.3 \\
\hline $\begin{array}{l}\text { Piperazine } \\
\text { (mono) }\end{array}$ & 55.5 & 41 & $\begin{array}{r}+0.347 \\
-0.176\end{array}$ & - & -0.306 & -0.374 & -0.509 & -4.49 & 2.8 \\
\hline
\end{tabular}

The following designations are used: $q$ is electronic charge, $\pi$ is hydrophobicity (calculated Hansch $\pi$-constant), $\Sigma q$ is total electron density on the heteroatoms, $\mu$ is dipole moment, $\gamma$ is the corrosion inhibition coefficient for steel based on electrochemical measurements, $\triangle \mathrm{JPD}$ (steel) is the junction potential difference upon adsorption on steel. The molecular masses of the amides are similar (from 349 to 365), so similarity of their molecular sizes can be assumed and its variation can be neglected in subsequent considerations. The same is true for salts (MM from 367 to 383).

The calculated parameters were taken from [1]. The cathodic and anodic polarization curves in the presence of inhibitors were recorded in a solution containing $30 \mathrm{mg} / \mathrm{dm}^{3}$ $\mathrm{NaCl}$ and $10 \mathrm{~g} / \mathrm{dm}^{3} \mathrm{Na}_{2} \mathrm{SO}_{4}$. The inhibitor film on specimen surfaces was formed in $1 \%$ solution of an inhibitor in isopropanol (amides) or in an aqueous emulsion containing $1 \mathrm{~g} / \mathrm{dm}^{3}$ of an inhibitor (salts). A steel specimen was kept for $60 \mathrm{~min}$ in an isopropanolic solution or in an aqueous emulsion, then dried for $60 \mathrm{~min}$ in air, and immediately placed into the cell for recording of polarization curves. Electrochemical measurements were carried out on carbon steel 20 using the common procedure, in a standard electrochemical cell with divided anodic and cathodic spaces. Platinum auxiliary electrodes were used. The potential of the working electrode was measured relative to a saturated silver chloride electrode $(E=0.202 \mathrm{~V})$. All potentials in the text are given with respect to saturated silver chloride electrode. Polarization curves were recorded in the potential range from $-1.25 \mathrm{~V}$ to $0.05 \mathrm{~V}$ in the positive direction, without preliminary cathodic activation of the electrode.

Extrapolation of linear cathodic and anodic regions in the polarization curves in semilogarithmic coordinates gave the free corrosion potential $\left(E_{\text {cor }}\right)$ and the logarithm of corrosion current density $\left(\lg i_{\text {cor }}\right)$ in the intersection point of the linear regions. The current densities were used to calculate the corrosion inhibition coefficients $\left(\gamma_{i}\right)$ and the corresponding protection effects $\left(Z_{\mathrm{i}}\right)$ using the formula:

$$
\gamma_{i}=\frac{i}{i^{\prime}}
$$


The electron work functions from the metal were determined using the capacitor method with direct reading of the junction potential difference (JPD). The «ПоверхностьИІ» ("Poverkhnost'-I1") instrument is a miniaturized high-sensitivity digital electrometer intended for measurement of the difference of surface potentials between the metal surface studied (M) and the measuring electrode (ME). Metal specimens of Steel 10 and M1 copper sized $50 \times 50 \times(2-3) \mathrm{mm}$ were polished, degreased with hexane, and dried for 5 min in air. After that, the first JPD was measured $\left(\mathrm{JPD}_{1}\right)$. After $\mathrm{JPD}_{1}$ was measured, the specimen was placed into a $1 \%$ isopropanolic solution of an inhibitor, kept there for $1 \mathrm{~h}$, then removed from the solution, transferred into a desiccator with calcium chloride, and kept there for $1 \mathrm{~h}$. After drying in the desiccator, the second JPD was measured $\left(\mathrm{JPD}_{2}\right)$, and the specimens with adsorbed inhibitor were again placed into a desiccator. The total time difference between the first two measurements followed by $\triangle$ JPD determination was $2 \mathrm{~h}$.

Approximation of experimental data for compliance with certain mathematical relationships was carried out using the MATLAB 6.5 vector-matrix laboratory. The "SVD" operator was not required in these approximations. To achieve the minimum calculation errors, it was sufficient to use direct algebraic mathematical processing of source data with $1^{\text {st }}$ and $2^{\text {nd }}$ degree polynomials.

The resulting polynomials of degrees $1 \ldots s$ in have the following general scalar form:

$$
y_{p}=b_{1} x_{1}+b_{2} x_{2}+b_{3} x_{3}+b_{4} x_{4}+. .+b_{5} x_{1}^{2}+b_{6} x_{2}^{2}+b_{7} x_{3}^{2}+b_{8} x_{4}^{2}+. .+b_{k} x_{1}^{s}
$$

and allow one, if required, to perform easy fast computations on a calculator based on approximation coefficients $b_{1}, b_{1}, \ldots b_{k}$.

The calculation was carried out by direct algebraic mathematical processing of source data using the following designations:

$F$ - calculated starting parameter $Y$,

$\mathrm{D} F=F-Y-$ calculated error of the computations,

$A$ - summary table of computation results,

$B$ - approximating polynomial coefficients.

A $1^{\text {st }}$ degree polynomial proved to be sufficient for high accuracy computations.

\section{Computation program:}

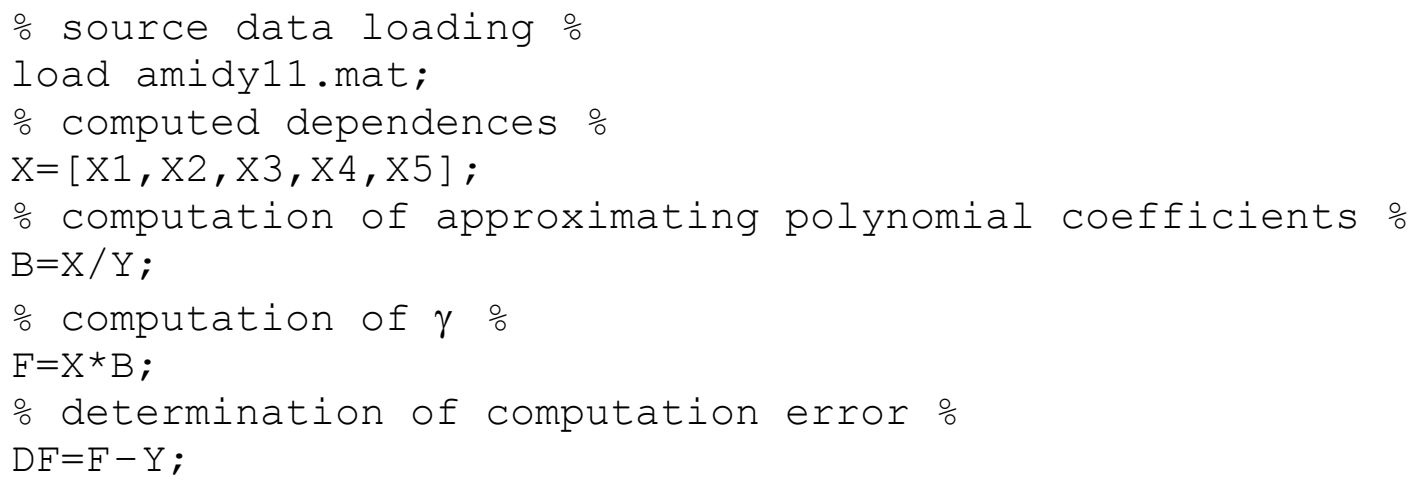


o summary table of computation results $\frac{\circ}{0}$

$\mathrm{A}=[\mathrm{Y}, \mathrm{F}, \mathrm{DF}]$;

Let us consider the following variants of correlation.

\section{Variant 1.}

\section{Oleic acid amides}

The general equation has the form: $\gamma=f\left(\Delta \mathrm{JPD}, q_{\mathrm{N}_{\mathrm{sp}}}, q_{\mathrm{O}_{\mathrm{sp}}}, \pi, \mu\right)$.

Table 3. Source data for the computation.

\begin{tabular}{ccccccc}
\hline & \multicolumn{7}{c}{ Designations } \\
\cline { 2 - 6 } Amide of: & $\mathbf{Y}$ & $\mathbf{X 1}$ & $\mathbf{X 2}$ & $\mathbf{X 3}$ & $\mathbf{X 4}$ & $\mathbf{X 5}$ \\
\cline { 2 - 6 } & $\boldsymbol{\gamma}$ & $\begin{array}{c}\boldsymbol{\Delta J P D} \\
\mathbf{s t e e l}\end{array}$ & $\boldsymbol{q}\left(\mathrm{N}_{\mathrm{sp}^{3}}\right)$ & $\boldsymbol{q}\left(\mathrm{O}_{\mathrm{sp}^{2}}\right)$ & $\boldsymbol{\pi}$ & $\boldsymbol{\mu}$ \\
\hline Hexylamine & 4.6 & 154 & -0.212 & -0.372 & 9.36 & 4.0 \\
Cyclohexylamine & 12.5 & 203 & -0.216 & -0.363 & 8.83 & 3.6 \\
Piperidine & 100 & 34 & -0.165 & -0.375 & 7.15 & 3.6 \\
Morpholine & 104 & 256 & -0.155 & -0.373 & 6.47 & 3.0 \\
\hline
\end{tabular}

Table 4. Computation results.

\begin{tabular}{|c|c|c|c|}
\hline \multicolumn{3}{|c|}{ Matrix A } & \multirow{2}{*}{$\begin{array}{c}\text { Coefficients } \\
\text { B }\end{array}$} \\
\hline $\mathbf{Y}$ & $\mathbf{F}$ & DF & \\
\hline 4.6 & 4.2763 & $1.4388 \mathrm{e}-013$ & -0.10619 \\
\hline 12.5 & 12.902 & $-2.8422 \mathrm{e}-014$ & 0 \\
\hline 100 & 100.02 & $1.4211 \mathrm{e}-013$ & $\begin{array}{l}-1029.2 \\
-34.049\end{array}$ \\
\hline 104 & 103.85 & $-5.6843 \mathrm{e}-014$ & -10.8 \\
\hline
\end{tabular}

Data for piperazine amide that had low efficiency due to poor solubility, which is considerably lower than that required to form an inhibitor film, was not used in the calculations. The poor solubility is apparently because the final product contains a considerable admixture of piperazine diamide that is poorly soluble in the majority of organic solvents.

The calculated inhibition coefficient for piperazine is:

$$
\boldsymbol{Y}(\gamma)=-0.10619 \cdot 94-1029.2 \cdot(-0.375)-34.049 \cdot 5.06-10.8 \cdot 3.7=163.72 \text {. }
$$




\section{Oleic acid salts}

The general equation has the form: $\gamma=f\left(\Delta \mathrm{JPD}, q_{\mathrm{N}_{\mathrm{sp}}}, q_{\mathrm{O}_{\mathrm{sp}}}, \pi, \mu\right)$.

Table 5. Source data for the computation.

\begin{tabular}{|c|c|c|c|c|c|c|}
\hline \multirow{3}{*}{ Salt of: } & \multicolumn{6}{|c|}{ Designations } \\
\hline & $\mathbf{Y}$ & $\mathbf{X} 1$ & $\mathbf{X} 2$ & $\mathbf{X 3}$ & X4 & X5 \\
\hline & $\gamma$ & $\begin{array}{c}\Delta J P D \\
\text { steel }\end{array}$ & $q\left(\mathrm{~N}_{\mathrm{sp}^{3}}\right)$ & $q\left(\mathrm{O}_{\mathrm{sp}^{3} \mathrm{salt}}\right)$ & $\pi$ & $\boldsymbol{\mu}$ \\
\hline Cyclohexylamine & 8.3 & 129 & 0.361 & -0.326 & 3.82 & 2.0 \\
\hline Hexylamine & 9.98 & 103 & 0.406 & -0.281 & 3.63 & 2.5 \\
\hline Morpholine & 33.3 & 92 & 0.351 & -0.372 & -1.24 & 1.4 \\
\hline Piperidine & 35.4 & 111 & 0.341 & -0.393 & -1.49 & 3.3 \\
\hline $\begin{array}{l}\text { Piperazine } \\
\text { (mono) }\end{array}$ & 55.5 & 41 & $\begin{array}{c}0.347 \\
-0.176\end{array}$ & -0.374 & -4.49 & 2.8 \\
\hline
\end{tabular}

Table 6. Computation results.

\begin{tabular}{cccc}
\hline & Matrix A & & \multicolumn{2}{c}{$\begin{array}{c}\text { Coefficients } \\
\text { B }\end{array}$} \\
\hline Y & F & DF & -0.24873 \\
9.3 & 8.345 & 0.044965 & 0.053182 \\
33.3 & 9.9441 & -0.03586 & -137.16 \\
35.4 & 33.274 & -0.02566 & -2.0764 \\
55.5 & 35.396 & -0.00426 & 1.8149 \\
\hline
\end{tabular}

\section{Variant 2}

\section{Oleic acid amides}

The general equation has the form: $\Delta \mathrm{JPD}=f\left(q_{\mathrm{N}_{\mathrm{sp}^{3}}}, q_{\mathrm{O}_{\mathrm{sp}^{2}}}, \pi, \mu\right)$. 
Table 7. Source data for the computation.

\begin{tabular}{cccccc}
\hline & \multicolumn{5}{c}{ Designations } \\
\cline { 2 - 5 } Amide of: & $\mathbf{Y}$ & $\mathbf{X 1}$ & $\mathbf{X 2}$ & $\mathbf{X 3}$ & $\mathbf{X 4}$ \\
\cline { 2 - 5 } & $\begin{array}{c}\mathbf{\Delta J P D} \\
\text { steel }\end{array}$ & $\boldsymbol{q}\left(\mathrm{N}_{\mathrm{sp}^{3}}\right)$ & $\boldsymbol{q}\left(\mathrm{O}_{\mathrm{sp}^{2}}\right)$ & $\boldsymbol{\pi}$ & $\boldsymbol{\mu}$ \\
\hline Hexylamine & 154 & -0.212 & -0.372 & 9.36 & 4.0 \\
Cyclohexylamine & 203 & -0.216 & -0.363 & 8.83 & 3.6 \\
Morpholine & 256 & -0.155 & -0.373 & 6.47 & 3.0 \\
Piperazine & 94 & -0.168 & -0.375 & 5.06 & 3.7 \\
Piperidine & 34 & -0.165 & -0.375 & 7.15 & 3.6 \\
\hline
\end{tabular}

The computation program is provided for approximation with a $2^{\text {nd }}$ order polynomial because approximation with a $1^{\text {st }}$ order polynomial results in considerable computation errors:

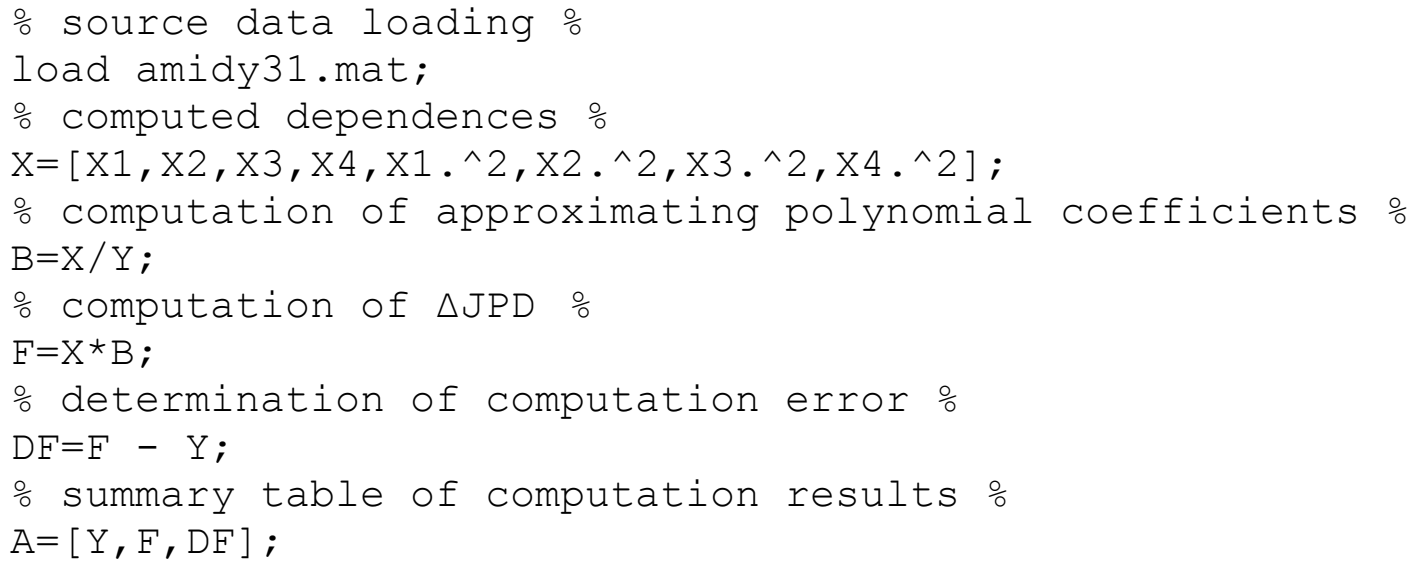

Table 8. Computation results.

\begin{tabular}{cccc}
\hline & Matrix A & & \multicolumn{2}{c}{ Coefficients } \\
B & DF & 0 \\
\hline Y & F & $-5.0022 \mathrm{e}-012$ & -5218.2 \\
203 & 154 & $-4.0927 \mathrm{e}-0 \mathrm{~s} 12$ & -674.13 \\
256 & 203 & $-1.5916 \mathrm{e}-012$ & 672.3 \\
94 & 256 & $-4.5475 \mathrm{e}-013$ & 0 \\
& 94 & & 0 \\
34 & 34 & $-1.3642 \mathrm{e}-012$ & 50.813 \\
& & & -163.64 \\
\hline
\end{tabular}




\section{Oleic acid salts}

The general equation has the form: $\Delta \mathrm{JPD}=f\left(q_{\mathrm{N}_{\mathrm{sp}^{3}}}, q_{\mathrm{O}_{\mathrm{sp}}}, q_{\mathrm{O}_{\mathrm{sp}^{3} \text { salt }}}, \pi, \mu\right)$.

The computation error is completely similar to that presented in Variant 1 (amides) for approximation with a $1^{\text {st }}$ order polynomial.

Table 9. Source data for the computation.

\begin{tabular}{ccccccc}
\hline & \multicolumn{5}{c}{ Designations } \\
\cline { 2 - 6 } Salt of: & $\mathbf{Y}$ & $\mathbf{X 1}$ & $\mathbf{X 2}$ & $\mathbf{X 3}$ & $\mathbf{X} 4$ & $\mathbf{X 5}$ \\
\cline { 2 - 6 } & $\begin{array}{c}\boldsymbol{\Delta} \mathbf{J P D} \\
\mathbf{s t e e l}\end{array}$ & $\boldsymbol{q}\left(\mathrm{N}_{\mathrm{sp}^{3}}\right)$ & $\boldsymbol{q}\left(\mathrm{O}_{\mathrm{sp}^{2} \text { salt }}\right)$ & $\boldsymbol{q}\left(\mathrm{O}_{\mathrm{sp}^{3} \text { salt }}\right)$ & $\boldsymbol{\pi}$ & $\boldsymbol{\mu}$ \\
\hline Hexylamine & 103 & 0.406 & -0.325 & -0.281 & 3.63 & 2.5 \\
Cyclohexylamine & 129 & 0.361 & -0.376 & -0.326 & 3.82 & 2.0 \\
Piperidine & 111 & 0.341 & -0.354 & -0.393 & -1.49 & 3.3 \\
Morpholine & 92 & 0.351 & -0.353 & -0.372 & -1.24 & 1.4 \\
Piperazine & 41 & -0.176 & -0.306 & -0.374 & -4.49 & 2.8 \\
\hline
\end{tabular}

Table 10. Computation results.

Matrix A

\begin{tabular}{cccc}
\hline Y & F & DF & B \\
\hline 103 & 103 & $-2.8422 \mathrm{e}-014$ & -45.699 \\
129 & 129 & $8.5265 \mathrm{e}-014$ & 4685.1 \\
111 & 111 & $1.1369 \mathrm{e}-013$ & -5128.8 \\
92 & 92 & $-1.7053 \mathrm{e}-013$ & 79.358 \\
41 & 41 & $5.6843 \mathrm{e}-013$ & -34.02 \\
\hline
\end{tabular}

\section{Variant 3}

\section{Oleic acid amides}

The general equation has the form: $\Delta \mathrm{JPD}=f\left(q_{\mathrm{N}_{\mathrm{sp}^{3}}}, q_{\mathrm{O}_{\mathrm{sp}}{ }^{2}}, \pi, \mu\right)$.

The computation program is completely similar to that presented in Variant 2 (amides) for approximation with a $2^{\text {nd }}$ order polynomial because approximation with a $1^{\text {st }}$ order polynomial results in considerable computation errors. 
Table 11. Source data for the computation.

\begin{tabular}{cccccc}
\hline \multirow{2}{*}{ Amine } & \multicolumn{5}{c}{ Designations } \\
\cline { 2 - 5 } & $\mathbf{Y}$ & $\mathbf{X 1}$ & $\mathbf{X 2}$ & $\mathbf{X 3}$ & $\mathbf{X 4}$ \\
\cline { 2 - 5 } & $\begin{array}{c}\boldsymbol{\Delta} \mathbf{J P D} \\
\mathbf{C o p p e r}\end{array}$ & $\boldsymbol{q}\left(\mathrm{N}_{\mathrm{sp}^{3}}\right)$ & $\boldsymbol{q}\left(\mathrm{O}_{\mathrm{sp}^{2}}\right)$ & $\boldsymbol{\pi}$ & $\boldsymbol{\mu}$ \\
\hline Cyclohexylamine & 121 & -0.216 & -0.363 & 8.83 & 3.6 \\
Morpholine & 83 & -0.155 & -0.373 & 6.47 & 3.0 \\
Piperidine & 79 & -0.165 & -0.375 & 7.15 & 3.6 \\
Hexylamine & 72 & -0.212 & -0.372 & 9.36 & 4.0 \\
Piperazine & 42 & -0.172 & -0.375 & 5.06 & 3.7 \\
\hline
\end{tabular}

Table 12. Computation results.

\begin{tabular}{cccc}
\hline & Matrix A & & \multicolumn{2}{c}{$\begin{array}{c}\text { Coefficients } \\
\text { B }\end{array}$} \\
\hline Y & F & DF & 0 \\
& 121 & $-4.5475 \mathrm{e}-013$ & 2090 \\
83 & 83 & $1.1369 \mathrm{e}-013$ & 29.441 \\
79 & 79 & $-1.1369 \mathrm{e}-013$ & 453.68 \\
72 & 72 & $2.2737 \mathrm{e}-013$ & 0 \\
42 & 42 & 0 & -1.2121 \\
& & & -70.915 \\
\hline
\end{tabular}

\section{Conclusions}

1. The results of electrochemical studies and junction potential difference measurements indicate that oleic acid amides and salts are electron donors in case of adsorption on steel and predominantly inhibit the anodic metal ionization reaction.

2. A relationship has been shown between the inhibiting and electron-donating capability of the amides and salts synthesized, on the one hand, and the main physicochemical parameters, namely, the electron density on the hetero atoms responsible for adsorption on metals, as well as hydrophobicity and dipole moments of molecules, on the other hand.

3. It has been shown that it is possible to approximate the dependences of the inhibitive efficiency and adsorption capability of oleic acid amides and salts with high reliability and with minimum computation errors. 


\section{References}

1. A.I. Altsybeeva, V.V. Burlov and E.A. Tronova , Int. J. Corros. Scale Inhib., 2014, 3, no. 3, 160. doi: $10.17675 / 2305-6894-2014-3-3-160-166$

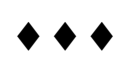

